"This document is the Accepted Manuscript version of a Published Work that appeared in final form in Inorganic Chemistry, copyright (02020 American Chemical Society after peer review and technical editing by the publisher. To access the final edited and published work see:

\title{
https://pubs.acs.org/doi/10.1021/acs.inorgchem.9b03595
}

\section{A Ru-bda complex with a dangling carboxylate group: synthesis and electrochemical properties}

\author{
Abolfazl Ghaderian, ${ }^{1,2}$ Jan Holub, ${ }^{1}$ Jordi Benet-Buchholz, ${ }^{1}$ Antoni Llobet, ${ }^{1,3, *}$ Carolina Gimbert-Suriñach, ${ }^{1, *}$ \\ ${ }^{1}$ Institute of Chemical Research of Catalonia (ICIQ), Barcelona Institute of Science and Technology, Av. Països \\ Catalans 16, 43007 Tarragona, Spain \\ ${ }^{2}$ Departament de Química Física i Inorgànica, Universitat Rovira i Virgili, Campus Sescelades, C/Marcel·lí \\ Domingo, s/n, 43007 Tarragona, Spain \\ ${ }^{3}$ Universitat Autònoma de Barcelona, Departament de Química, Cerdanyola del Vallès, 08193 Barcelona, Spain \\ *allobet@iciq.cat \\ *cgimbert@iciq.cat
}

\begin{abstract}
Ruthenium complexes containing the tetradentate 2,2'-bipyridine-6,6'-dicarboxylato (bda ${ }^{2-}$ ) equatorial ligand and ortho-subsituted pyridines in the axial position have been prepared and characterized using spectroscopic, crystallographic and electrochemical techniques. Complexes $[\mathrm{Ru}(\mathrm{Hbda})(\mathrm{DMSO})(\mathrm{pyC})] \quad(\mathbf{1})$ and [Ru(bda)(DMSO)(pyA)] (2) (where pyC is 2-pyridinecarboxylate, pyA is pyridine-2-ylmethanol and DMSO is dimethylsulfoxide) have been isolated in moderate to high yields. The solid state structures of (1-H) ${ }^{-}$and $\mathbf{2}$ reveal the strong chelate effect of the axial pyridine ligand that coordinates in a bidentate fashion leaving the bda ${ }^{2-}$ equatorial ligand coordinating in a tridentate mode. In solution, compound $\mathbf{2}$ shows a dynamic equilibrium between different coordination modes of the $\mathrm{bda}^{2-}$ and pyA ligands. This phenomenon does not occur for 1 because the carboxylate binds stronger than the labile alcohol in $\mathbf{2}$. Cyclic voltammetry analysis of $\mathbf{1}$ reveal a complex behavior with a $\mathrm{pH}$ independent wave at $E_{1 / 2}=1.12 \mathrm{~V}$ that is tentatively associated with the twoelectron $\mathrm{Ru}^{\mathrm{IV} / I I}$. In sharp contrast, complex 2 shows a $\mathrm{pH}$ dependent one-electron wave at $E_{1 / 2}=0.83 \mathrm{~V}(\mathrm{pH} 1)$, assigned to the proton couple electron transfer process of the $\mathrm{Ru} \mathrm{u}^{\mathrm{III} / \mathrm{II}}$ couple and a $\mathrm{pH}$ independent wave at $E_{1 / 2}$ $=1.06 \mathrm{~V}$ assigned to the $\mathrm{Ru} \mathrm{IV} / \mathrm{III}$ couple. Compound $\mathbf{2}$ was used to prepare complex $[\mathrm{Ru}(\mathrm{bda})(\mathrm{pic})(\mathrm{pyA})]$ (4). This complex is air sensitive and converts to complex $[R u(b d a)(p i c)(p y E)](5)$ (where pyE is methyl 2-pyridine carboxylate) in the presence of methanol. This oxidation also occurs by applying a positive potential to an aqueous solution of $\mathbf{4}$, producing the derivative $[\mathrm{Ru}(\mathrm{bda})(\mathrm{pic})(\mathrm{pyC})](\mathbf{3})$. Cyclic voltammetry of $\mathbf{3}$ shows two $\mathrm{pH}$ independent one-electron oxidation waves at $E_{1 / 2}=0.64 \mathrm{~V}$ and $E_{1 / 2}=1.0 \mathrm{~V}$, corresponding to the $\mathrm{Ru}^{\mathrm{III} / I I}$ and $\mathrm{Ru}^{\mathrm{IV} / \mathrm{III}}$ couples, respectively. In addition, a water oxidation catalytic wave appears at $E_{\text {onset }} \approx 1.4 \mathrm{~V}$. Foot of the wave analysis of this catalytic wave based on a water nucleophilic attack accounts for a TOF $\max =0.63-0.74 \mathrm{~s}^{-1}$.
\end{abstract}




\section{Key words}

Ruthenium, water oxidation catalysis, dynamic behavior, benzylic alcohol oxidation, ligand design 


\section{1-Introduction}

In the field of water oxidation to dioxygen catalysis, ruthenium complexes have played an important role not only allowing the elucidation of catalytic mechanisms but also generating the fastest and most rugged molecular catalysts reported to date. ${ }^{1}$ The recent advances have allowed the scientific community to identify a series of features that are crucial to reach turnover frequencies (TOFs) above $10^{4} \mathrm{~s}^{-1}$ and stabilities beyond millions of turnover numbers (TONs). ${ }^{2}$ Among them it is important to highlight the ligand robustness, the possibility to reach seven coordination number at high metal oxidation states and second coordination sphere effects. There are two families of complexes that comply with these requirements and are characterized by containing an equatorial polypyridine ligand with one or two carboxylate groups bound to the metal center. In particular, ruthenium complexes containing the tetradentate bda ${ }^{2-}\left(2,2^{\prime}\right.$-bipyridine-6,6'-dicarboxylato) ligand and pentadentate $\operatorname{tda}^{2-}\left(\left[2,2^{\prime}: 6^{\prime}, 2^{\prime \prime}\right.\right.$-terpyridine]-6,6"-dicarboxylato) ligand are those showing record rates and stabilities (see Figure 1 for catalyst precursors). ${ }^{3}$ The former bda family of complexes are known to follow a bimolecular mechanism in respect to $\mathrm{Ru}$ where two $\mathrm{Ru}$-oxo groups react in the key $\mathrm{O}-\mathrm{O}$ bond formation step (I2M) while the latter tda family of catalysts follows a water nucleophilic attack mechanism (WNA) assisted by the dangling carboxylate group in the equatorial ligand. The $\mathrm{K}-\mathrm{N}^{2} \mathrm{O}^{2}$ coordination fashion of the $\mathrm{bda}^{2-}$ ligands provides high electron density to the metal center mainly due to the two carboxylate groups that results in the lowest overpotential for water oxidation reaction based on ruthenium molecular complexes reported until now. On the other hand, the $\mathrm{k}-\mathrm{N}^{3} \mathrm{O}^{1}$ coordination mode of the tda ${ }^{2-}$ ligand, with only one carboxylate group bound to the metal center results in higher overpotential. However, the presence of a dangling carboxylate group in the $\mathrm{tda}^{2-}$ is key to provide fast catalysis through a WNA mechanism, and to incorporate such catalytic centers in conductive and semiconductive solid supports. ${ }^{2 a, 4}$ This is not straightforward with the bda family of complexes that follow an I2M mechanism, for which the incorporation into electrodes results in decomposition to ruthenium oxide due to the restricted mobility of the ruthenium centers once attached on a surface. ${ }^{5}$

In this work, we take inspiration from the best features of the bda and tda family of complexes and explore the synthesis of the complex $\left[R u^{\prime \prime \prime}(b d a)(p i c)(p y C)\right]$ where pic is 4-methylpyridine and pyC is 2pyridinecarboxylate (Figure 1, right). The complex has a similar coordination sphere around the metal center to that of the bda family (Figure 1, left), this means, 4 neutral pyridine ligands and 2 anionic carboxylate ligands. The main difference is that the second coordinated carboxylate group is provided by an axial pyridine ligand instead of the equatorial bda $\mathrm{bl}^{2-}$ ligand. At the same time, the target complex has a dangling carboxylate that may assist a water nucleophilic attack to the high valent Ru-oxo species, in a similar fashion to that of the tda complex (Figure 1, middle). 


\section{Reported}

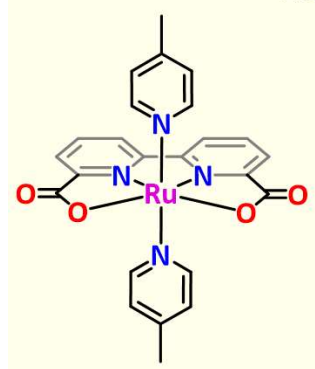

$\left[\mathrm{Ru}\right.$ "l (bda) $\left.(\mathrm{pic})_{2}\right]$

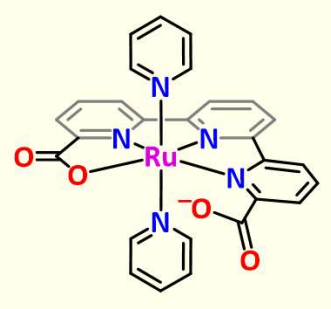

$\left[R u^{\prime \prime}(\mathrm{tda})(\mathrm{py})_{2}\right]$

\section{This work}

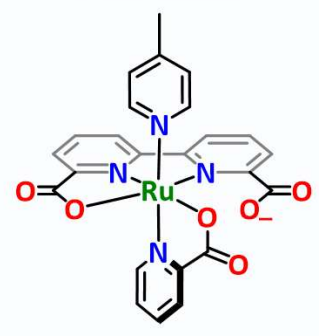

$\left[R u^{\prime \prime \prime}(b d a)(p i c)(p y C)\right]$

Figure 1. Left) Ruthenium complexes that are precursors of water oxidation to dioxygen catalysts. Right) Catalyst designed in this work. Abbreviations: bda ${ }^{2-}$ is 2,2'-bipyridine-6,6'-dicarboxylato, $\mathrm{tda}^{2-}$ is $\left[2,2^{\prime}: 6^{\prime}, 2^{\prime \prime}\right.$-terpyridine]-6,6"dicarboxylato, pic is 4-methylpyridine, py is pyridine and pyC is 2pyridinecarboxylato. 


\section{2-Experimental Section}

Synthetic materials: The bda ${ }^{2-}$ ligand 2,2'-bipyridine-6,6'-dicarboxylato ${ }^{3 a}$ and the ruthenium precursor $\left[\mathrm{Ru}(\mathrm{DMSO}){ }_{4} \mathrm{Cl}_{2}\right]^{6}$ and intermediate $[\mathrm{Ru}(\mathrm{bda})(\mathrm{DMSO})(\mathrm{X})](\text { where } \mathrm{X}=\mathrm{MeOH} \text { or DMSO})^{7}$ were prepared according to the literature. The ortho-functionalized pyridines 2-pyridinecarboxylic acid (HpyC), pyridine-2-ylmethanol (pyA) and other reagents including 4-picoline (pic) were obtained from Sigma-Aldrich and used as received. When required, solvents were dried by following the standard procedures, distilled under nitrogen and used immediately. High purity de-ionized water used for the electrochemistry experiments was obtained by passing distilled water through a nanopure Milli-Q water purification system. For other spectroscopic and electrochemical studies, HPLC-grade solvents were used. Instrumentation and methods: A $500 \mathrm{MHz}$ Bruker spectrometer was used to carry out NMR spectroscopy. ESI-Mass experiments were performed by using micromass Q-TOF mass spectrometer. UV/Vis spectroscopy was performed on a Cary 50 (Varian) UV/Vis spectrophotometer in $0.1 \mathrm{~cm}$ quartz cuvettes. Elemental analyses were carried out on Perkin-Elmer $240 \mathrm{C}$ elemental analyzer. The $\mathrm{pH}$ of the electrolytic solutions was determined by a $\mathrm{pH}$ meter (CRISON, Basic 20+) calibrated before measurements through a standard solutions at $\mathrm{pH} 4.01,7.00$ and 9.21. Manometric measurements were performed on a Testo 521 differential pressure manometer with an operating range of $0.1-10 \mathrm{kPa}$ and accuracy within $0.5 \%$ of the measurements. The manometer was coupled to thermostatic reaction vessels for dynamic monitoring of the headspace pressure above each reaction solution. The manometer's secondary ports were connected to thermostatic reaction vessels containing the same solvents and headspace volumes as the sample vials. Each measurement for a reaction solution $(2.0 \mathrm{~mL})$ was performed at $298 \mathrm{~K}$. Electrochemical techniques and materials: all electrochemical experiments were performed with an IJ-Cambria CHI-660 potentiostat using a one-compartment three-electrode cell for cyclic voltammetry (CV) and differential pulse voltammetry (DPV) or two compartment cell for bulk electrolysis. $E_{1 / 2}$ values reported in this work were estimated from CV experiments as the average of the oxidative and reductive peak potentials $\left(E_{\mathrm{p}, \mathrm{a}}+E_{\mathrm{p}, \mathrm{c}}\right) / 2$ or from DPV. All the potentials reported in this work were measured $\mathrm{vs} \mathrm{Hg} / \mathrm{Hg}_{2} \mathrm{SO}_{4}\left(\mathrm{~K}_{2} \mathrm{SO}_{4}\right.$ saturated) as reference electrode (unless indicated), and converted to NHE by adding $0.648 \mathrm{~V}$. Glassy carbon $\operatorname{disk}\left(\phi=0.3 \mathrm{~cm}, \mathrm{~S}=0.07 \mathrm{~cm}^{2}\right)$ and Pt disk were used as Working Electrode (WE) and Counter Electrode (CE), respectively, unless explicitly mentioned. Glassy carbon electrodes were polished with $0.05 \mu \mathrm{m}$ alumina $\left(\mathrm{Al}_{2} \mathrm{O}_{3}\right)$ and rinsed with water. CVs and DPs were $i R$ compensated at $85 \%$. Cyclic Voltammograms (CV) were recorded at $100 \mathrm{mV} \cdot \mathrm{s}^{-1}$ scan rate, unless explicitly metnioned. The DPV parameters were $\Delta E=4 \mathrm{mV}$, Amplitude $=50 \mathrm{mV}$, Pulse width $=0.05 \mathrm{~s}$, Sampling width $=0.0167 \mathrm{~s}$, Pulse period $=0.5 \mathrm{~s}$. The electrolytes used in the electrochemical experiments were $0.1 \mathrm{M}$ triflic acid solution for $\mathrm{pH} 1$ and $I=0.1 \mathrm{M}$ phosphate buffer solutions with desired the $\mathrm{pH}$. For routine bulk electrolysis experiments, a Pt mesh (cylindrical Pt mesh electrode, $\varnothing: 10$ $\mathrm{mm}$ ) was used as a WE, another Pt grid (square Pt mesh $20 * 20 \mathrm{~mm}$ ) as a $\mathrm{CE}$ and a $\mathrm{Hg} / \mathrm{Hg}_{2} \mathrm{SO}_{4}\left(\mathrm{~K}_{2} \mathrm{SO}_{4}\right.$ saturated) as a RE. 
Synthesis of the $[\mathrm{Ru}(\mathrm{Hbda})(\mathrm{DMSO})(\mathrm{pyC})]$ (1). $[\mathrm{Ru}(\mathrm{bda})(\mathrm{DMSO})(\mathrm{X})](\mathrm{X}=\mathrm{MeOH}$ or DMSO) (150 mg, c.a. 0.3 $\mathrm{mmol}$ ) and pyridine-2-carboxylic acid ( $\mathrm{HpyC})(40 \mathrm{mg}, 0.32 \mathrm{mmol})$ were dissolved in anhydrous $\mathrm{MeOH}(200 \mathrm{~mL})$ and stirred $(600 \mathrm{rpm})$ at room temperature overnight under Ar. The product precipitated as a red powder, which was filtered off and washed with acetone $(1 \times 5 \mathrm{~mL}), \mathrm{Et}_{2} \mathrm{O}(3 \times 5 \mathrm{~mL})$ and dried under vacuum $(0.165$ mmol, 55\% yield). ${ }^{1} \mathrm{H} N M R\left(500 \mathrm{MHz}, \mathrm{D}_{2} \mathrm{O}\right): \delta(\mathrm{ppm})=2.47(\mathrm{~s}, 3 \mathrm{H}), 2.67(\mathrm{~s}, 3 \mathrm{H}), 7.49(\mathrm{~d}, J=7.72 \mathrm{~Hz}, 1 \mathrm{H}), 7.76$ (dd, J=4.93, $9.94 \mathrm{~Hz}, 1 \mathrm{H}$ ), 8.04 (d, J= 4.24 Hz, 2 H), 8.09 (t, J=7.96 Hz, 1 H), 8.14 (d, J=7.72, 1 H), 8.22 (t, J=7.98 $\mathrm{Hz}, 1 \mathrm{H}), 8.40$ (d, J=7.36, Hz 1 H), 8.56 (d, J=8.08 Hz, 1 H), 9.76 (d, J=5.52 Hz, 1 H). ${ }^{13} \mathrm{C}$ NMR (125 MHz, MeOD): $\delta=42.27,43.37,124.20,125.46,126.27,126.59,127.31,128.23,138.26,138.32,139.94,151.94,155.22$ ppm. UV/Vis $\left[\lambda_{\max }, \mathrm{nm}\left(\varepsilon, \mathrm{M}^{-1} \mathrm{~cm}^{-1}\right)\right]: 256$ (14698), 296 (20017), 396 (6083). Dark red single crystals of $\mathrm{Na}[\mathrm{Ru}(\mathrm{bda})(\mathrm{DMSO})(\mathrm{pyC})], \mathrm{Na}[\mathbf{1 - H}]$, suitable for X-ray diffraction studies formed after dissolving $\mathbf{1}$ in the minimum amount of $\mathrm{MeOH}$ at room temperature and left it in the fridge overnight, as a result of deprotonation of the carboxylic acid in $\mathbf{1}$ and precipitation with sodium countercation from traces of inorganic salts. Elemental analysis calcd (\%) for $\mathrm{C}_{20} \mathrm{H}_{16} \mathrm{~N}_{3} \mathrm{O}_{7} \mathrm{RuS}^{-} \cdot \mathrm{Na}^{+} \cdot 2 \mathrm{H}_{2} \mathrm{O} \cdot \mathrm{MeOH}\left(\mathrm{C}_{21} \mathrm{H}_{24} \mathrm{~N}_{3} \mathrm{NaO}_{10} \mathrm{RuS}\right): \mathrm{C} 39.75, \mathrm{H} 3.81, \mathrm{~N}$ 6.62. Found C 39.02, H 3.93, N 6.83. MS (ESI, positive mode, $\mathrm{MeOH}): m / z^{+}=589.95\left(\mathrm{M}+2 \mathrm{Na}^{+}\right)$.

Synthesis of the [Ru(bda)(DMSO)(pyA)] (2). [Ru(bda)(DMSO)(X)] (X= MeOH or DMSO) (200 mg, c.a. $0.4 \mathrm{mmol}$ ) and pyridine-2-ylmethanol (pyA) $(60.6 \mu \mathrm{l}, 0.8 \mathrm{mmol})$ were dissolved in anhydrous $\mathrm{MeOH}(20 \mathrm{~mL})$ and heated to reflux for $3 \mathrm{~h}$ under Ar. A red solid formed, which was filtered to remove unreacted solid ruthenium precursor. The filtered solution was concentrated by rotary evaporator and diethyl ether added inducing precipitation of compound 2, which was filtered and washed with additional diethyl ether $(0.38 \mathrm{mmol}, 95 \%$ yield). Single crystals of $\mathbf{2}$ were obtained by dissolving it in the minimum amount of methanol at room temperature and left in the fridge overnight. ${ }^{1} \mathrm{H} \mathrm{NMR}(500 \mathrm{MHz}, \mathrm{MeOD}): \delta(\mathrm{ppm})=3.09(\mathrm{~s}, 6 \mathrm{H}), 5.43(\mathrm{~s}, 2 \mathrm{H})$, $7.23(\mathrm{t}, J=6.32 \mathrm{~Hz}, 1 \mathrm{H}), 7.29$ (d, J=5.08 Hz, 1 H), 7.67 (d, J= $7.84 \mathrm{~Hz}, 1 \mathrm{H}), 7.92(\mathrm{t}, J=3.35 \mathrm{~Hz}, 1 \mathrm{H}), 8.06$ (d, J=7.64, $2 \mathrm{H}), 8.23(\mathrm{t}, J=7.92 \mathrm{~Hz}, 2 \mathrm{H}), 8.71(\mathrm{~d}, J=8.00 \mathrm{~Hz}, 2 \mathrm{H}) .{ }^{13} \mathrm{C}$ NMR $(125 \mathrm{MHz}, \mathrm{MeOD}): \delta=42.65,69.56,120.70$, $124.78,126.83,137.05,138.53,139.06,147.96,158.80,161.92,172.09 \mathrm{ppm}$. UV/Vis $\left[\lambda_{\max }, \mathrm{nm}\left(\varepsilon, \mathrm{M}^{-1} \mathrm{~cm}^{-1}\right)\right]$ : 242 (12018), 296 (26221), 407 (3691). Elemental analysis calcd (\%) for $\mathrm{C}_{20} \mathrm{H}_{19} \mathrm{~N}_{3} \mathrm{O}_{6} \mathrm{RuS} \cdot 2 \mathrm{H}_{2} \mathrm{O}\left(\mathrm{C}_{20} \mathrm{H}_{23} \mathrm{~N}_{3} \mathrm{O}_{8} \mathrm{RuS}\right)$ : $\mathrm{C} 42.40, \mathrm{H} 4.09, \mathrm{~N}$ 7.42. Found C 42.84, H 3.84, N 7.39. MS (ESI, positive mode, $\mathrm{MeOH}): \mathrm{m} / \mathrm{z}^{+}=553.9\left(\mathrm{M}+\mathrm{Na}^{+}\right)$. Synthesis of the [Ru(bda)(pic)(pyA)] (4). [Ru(bda)(DMSO)(pyA)] (2) (151 mg, $0.27 \mathrm{mmol}$ ) and 4-methylpyridine (pic) $(0.3 \mathrm{ml}, 3 \mathrm{mmol})$ were dissolved in anhydrous $\mathrm{MeOH}(20 \mathrm{~mL})$ and heated to reflux overnight under Ar. A dark-red solution appeared which was evaporated to dryness. The residual solid was purified by column chromatography on silica gel using DCM/methanol (100:17) as eluents. Compound $\mathbf{4}$ was isolated as a red solid (0.042 mmol, 15\% yield). ${ }^{1} \mathrm{H} \mathrm{NMR}(500 \mathrm{MHz}, \mathrm{MeOD}): \delta(\mathrm{ppm})=2.40(\mathrm{~s}, 3 \mathrm{H}), 4.72(\mathrm{~s}, 2 \mathrm{H}), 7.21(\mathrm{~d}, \mathrm{~J}=6.10 \mathrm{~Hz}$, $2 \mathrm{H}), 7.47(\mathrm{~m}, 2 \mathrm{H}), 7.83(\mathrm{~d}, J=7.60 \mathrm{~Hz}, 2 \mathrm{H}), 8.00$ (t, J=3.15 Hz, 1 H), 8.06 (t, J=7.90 Hz, 1 H), 8.16 (d, J=6.60, 2 H), 8.37 (t, J=7.85 Hz, 1 H), 8.60 (d, J=4.02 Hz, 2 H). ${ }^{13} \mathrm{C} \mathrm{NMR} \mathrm{(125} \mathrm{MHz,} \mathrm{MeOD):} \delta=19.36,55.96,123.34,124.93$, $125.86,127.44,129.63,134.81,136.70,149.71,150.30,151.44,151.58,159.10,171.31,173.31$. UV/Vis $\left[\lambda_{\max }\right.$, 
$\mathrm{nm}\left(\varepsilon, \mathrm{M}^{-1} \mathrm{~cm}^{-1}\right)$ ]: 255 (15100), 301 (22998), 346 (6430), 419 (5325), 422 (5591). Elemental analysis calcd (\%) for $\mathrm{C}_{24} \mathrm{H}_{20} \mathrm{~N}_{4} \mathrm{O}_{5} \mathrm{Ru} \cdot \mathrm{H}_{2} \mathrm{O} \cdot \mathrm{MeOH} \cdot \mathrm{DCM}\left(\mathrm{C}_{26} \mathrm{H}_{28} \mathrm{Cl}_{2} \mathrm{~N}_{4} \mathrm{O}_{7} \mathrm{Ru}\right)$ : C 45.89, $\mathrm{H}$ 4.15, N 8.23. Found C 45.79, H 3.65, N 8.56. MS (ESI, positive mode, $\mathrm{MeOH}): m / z^{+}=575.9\left[\mathrm{M}-\mathrm{H}^{+}+\mathrm{MeO}\right]$. Single crystals of derivative 5 were grown by dissolving $\mathbf{4}$ in DCM/methanol and by diffusion of diethyl ether under air. Compound $\mathbf{5}$ is the result of the oxidation of the benzylic alcohol in compound $\mathbf{4}$ to give the corresponding methyl ester group, see main text for discussion.

X-ray Crystallography. Data collection: Crystal structure determination for compounds 1 and $\mathrm{Na}_{2}\left[\mathrm{Ru}(\mathbf{b d a})_{2}\right]$ were carried out using a Rigaku diffractometer equipped with a Pilatus 200K area detector, a Rigaku MicroMax-007HF microfocus rotating anode with $\mathrm{MoK}_{\alpha}$ radiation, Confocal Max Flux optics and an Oxford Cryosystems low temperature device Cryostream 700 plus $\left(T=-173^{\circ} \mathrm{C}\right)$. Full-sphere data collection was used with $\omega$ and $\varphi$ scans. Programs used: Data collection and reduction with CrysAlisPro ${ }^{8} \mathrm{~V} / .60 \mathrm{~A}$ and absorption correction with Scale3 Abspack scaling algorithm ${ }^{9}$. Crystal structure determination for compounds $\mathbf{2}$ and $\mathbf{5}$ were carried out using a Apex DUO Kappa 4-axis goniometer equipped with an APPEX 2 4K CCD area detector, a Microfocus Source E025 luS using MoK $_{\alpha}$ radiation, Quazar MX multilayer Optics as monochromator and an Oxford Cryosystems low temperature device Cryostream 700 plus $\left(T=-173{ }^{\circ} \mathrm{C}\right)$. Crystal structure determination for samples Full-sphere data collection was used with $\omega$ and $\varphi$ scans. Programs used: Data collection APEX- $2^{10}$, data reduction Bruker Saint ${ }^{11} \mathrm{~V} / .60 \mathrm{~A}$ and absorption correction SADABS. ${ }^{12}$ Structure Solution and Refinement: Crystal structure solution was achieved using the computer program SHELXT ${ }^{13}$. Visualization was performed with the program SHELXle. ${ }^{14}$ Missing atoms were subsequently located from difference Fourier synthesis and added to the atom list. Least-squares refinement on $\mathrm{F}^{2}$ using all measured intensities was carried out using the program SHELXL 2015. ${ }^{15}$ All non-hydrogen atoms were refined including anisotropic displacement parameters. Comments to the structures: $\mathrm{Na}_{2}\left[\mathbf{R u}(\mathbf{b d a})_{2}\right]$ : The asymmetric unit contains one molecule of the metal complex, two sodium cations, 1.65 molecules of water (partially disordered) and 4.60 molecules of methanol (partially disordered). The distance between the two independent Sodium cations is of $3.42 \AA$ and they are additionally connected through oxygen bridges coming from the dimethyl sulfoxide groups. 1: The asymmetric unit contains one molecule of the metal complex, a sodium cation, two water molecules and a methanol molecule. The sodium cation is coordinated to the metal complex through the dimethylsulfoxide group and two carboxylates. Additionally, the sodium cation is coordinated to the two water molecules and forms a dimer with another sodium cation. The distance between sodium atoms is of $3.7 \AA$ and they are connected through oxygen bridges coming from the dimethyl sulfoxide groups. The dimer formed by the sodium cations has $\mathrm{Ci}$ symmetry. 2: The asymmetric unit contains two independent molecules of the metal complex and highly disordered solvent molecules. A diethyl ether molecule with an occupancy of $50 \%$ is disordered around an inversion center shared with the neighboring unit cell and could be refined properly. A second highly disordered solvent molecule, which could contain 
diethyl ether or ethanol, could not be refined properly. In order to avoid these highly disordered solvent molecule the program SQUEEZE ${ }^{16}$ was applied to remove it from the electron density. 5: The asymmetric unit contains one independent molecule of the metal complex, one methanol molecule and half water molecule disordered in two positions (occupancy 0.3:0.2). 


\section{3-Results}

\section{3-1-Preparation and characterization of compounds 1-4}

The synthesis of complexes with general formula $\left[R u(b d a)\left(p y^{\prime}\right)\left(p y^{\prime \prime}\right)\right]$ where py' and py" are two different monodentate pyridine ligands can be achieved by two consecutive substitution reactions from $[\mathrm{Ru}(\mathrm{bda})(\mathrm{DMSO})(\mathrm{X})]$ where $\mathrm{X}$ is $\mathrm{MeOH}$ or DMSO (Scheme 1). ${ }^{17,7}$ The intermediate $[\mathrm{Ru}(\mathrm{bda})(\mathrm{DMSO})(\mathrm{X})]$ was obtained as a brown solid with a yield of $c a .67 \%$, along with a side product identified as the bis-substituted bda complex $\left[\mathrm{Ru}(\mathrm{bda})_{2}\right]^{2-}(\mathrm{ca} .5-7 \%)$. The latter compound has never been reported before, it has been fully characterized by NMR spectroscopy, single crystal x-ray diffraction (XRD) and elemental analysis as described in detail in the experimental section and the supporting information.

The reaction of $[\mathrm{Ru}(\mathrm{bda})(\mathrm{DMSO})(\mathrm{X})]$ with 2-pyridinecarboxylic acid (HpyC) affords complex 1 in $55 \%$ yield, which has been fully characterized by spectroscopic, analytic and electrochemical techniques. Single crystals of the anionic complex [Ru(bda)(DMSO)(pyC)], (1-H)-, suitable for XRD studies were obtained and its ORTEP plot is shown in Figure 2. Compound $(\mathbf{1 - H})^{-}$is a Ru" complex with pseudo-octahedral geometry with Ru-N, Ru$\mathrm{O}$ and Ru-S bond distances similar to those of other Ru complexes of the bda family. ${ }^{18}$ Interestingly, the bda ${ }^{2-}$ ligand coordinates in a $\mathrm{k}-\mathrm{N}^{2} \mathrm{O}^{1}$ fashion while the pyC ligand acts as a bidentate ligand with the carboxylate occupying the fourth equatorial position. As a consequence, the angle O-Ru-O formed by the equatorial ligands is $93.72^{\circ}$, close to the $90^{\circ}$ expected for a perfect octahedral geometry. These angle values are in sharp contrast to those observed for Ru complexes, where the bda ${ }^{2-}$ coordinates in a $\mathrm{k}-\mathrm{N}^{2} \mathrm{O}^{2}$ mode resulting in broad O-Ru-O angles in the range of $121^{\circ}$ to $124^{\circ} .{ }^{18 a}, 19$ The axial positions in 1 are occupied by DMSO and the pyridine of the pyC ligand. The ${ }^{1} \mathrm{H}$ NMR spectrum of 1 in deuterated water shows a non-symmetric nature of the two pyridine rings of the bda ${ }^{2-}$ ligand, even at high temperature, and indicates that the structure just described in the solid state is maintained in solution (Figure S7 and Figure S12).

The reaction of $\mathbf{1}$ with 4-picoline (pic) to afford the targeted compound $[\mathrm{Ru}(\mathrm{bda})(\mathrm{pic})(\mathrm{pyC})]^{-}, \mathbf{3}$, was not possible after several attempts at high temperature, long reaction times and different combination of solvents. The main products observed after reaction were the starting materials, $[\operatorname{Ru}(b d a)(p i c)(D M S O)]$ and $\left[\mathrm{Ru}(\mathrm{bda})(\mathrm{pic})_{2}\right]$.

In view of the unsuccessful reaction to prepare $\mathbf{3}$ using $\mathbf{1}$ as precursor, an alternative route was designed, based on the intermediate $[\operatorname{Ru}(b d a)(D M S O)(p y A)], 2$ in Scheme 1, that contains an hydroxymethyl group in the orto position of the axial pyridine. Compound $\mathbf{2}$ was prepared in $95 \%$ yield starting from precursor $[\mathrm{Ru}(\mathrm{bda})(\mathrm{DMSO})(\mathrm{X})]$ (where $\mathrm{X}=\mathrm{MeOH}$ or DMSO). The solid state structure of the neutral complex $\mathbf{2}$ was determined by single crystal XRD and its ORTEP plot is shown in Figure 2. The alcohol in the axial ligand is coordinating the metal center leaving a dangling carboxylate of the bda- ligand, that binds in a $\mathrm{K}-\mathrm{N}^{2} \mathrm{O}^{1} \mathrm{mode}$. It shows an analogous geometry to that of compound $\mathbf{1}$ with similar bond distances and angles. 


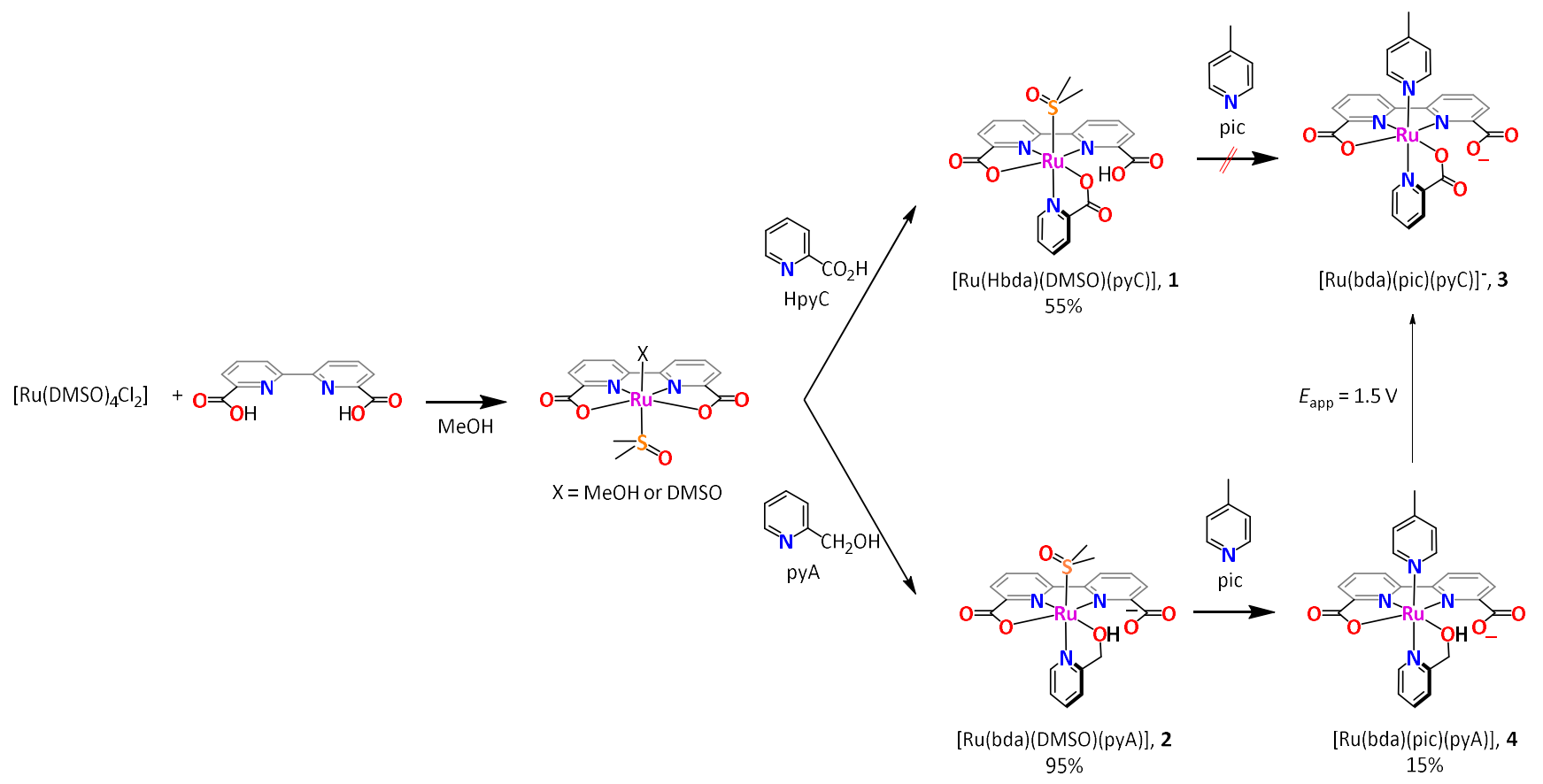

Scheme 1. Synthetic scheme for the preparation of $[R u(H b d a)(D M S O)(p y C)](\mathbf{1}),[R u(b d a)(D M S O)(p y A)](2),[R u(b d a)(p i c)(p y C)]^{-}(\mathbf{3})$, and $[R u(b d a)(p i c)(p y A)](4)$.

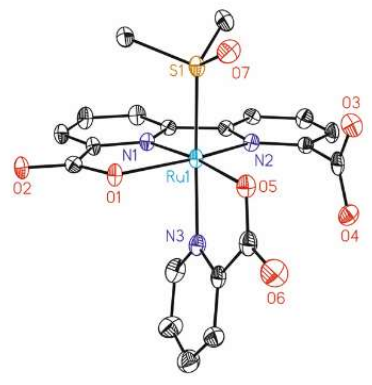

$(1-\mathrm{H})^{-}$

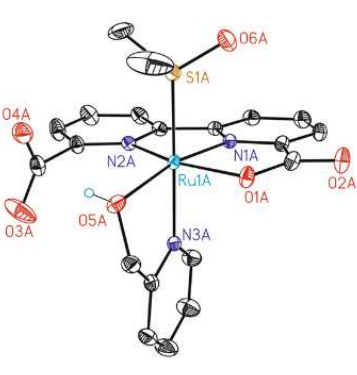

2

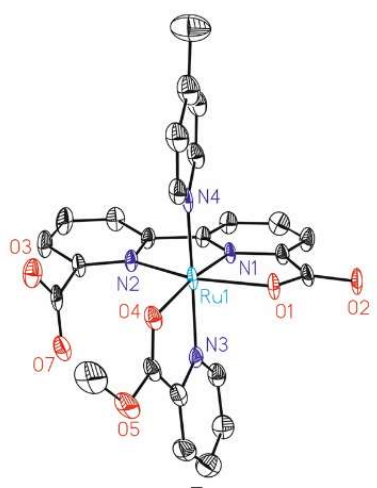

5

Figure 2. ORTEP plots at 50\% probability for $(\mathbf{1}-\mathrm{H})^{-}, \mathbf{2}$ and $\mathbf{5} . \mathrm{H}$ atoms are omitted for clarity except for the $\mathrm{H}$ atom coordinated to oxygen atom in $\mathbf{2}$.

On the other hand, NMR characterization of $\mathbf{2}$ in methanol at room temperature shows only one set of resonances for the two pyridines of the $\mathrm{bda}^{2-}$ ligand, indicative of a symmetric geometry as opposed to what we observed in the solid state (Figure 3, blue spectrum). By lowering the temperature to $223 \mathrm{~K}$, the bda- ligand resonances become broad suggesting a fast equilibrium between species with different connectivity as indicated in the sequence of reactions in the top of Figure 3. These types of equilibria have been observed before for ruthenium complexes containing the $\mathrm{bda}^{2-}$ and $\mathrm{tda}^{2-}$ equatorial ligands. ${ }^{3 \mathrm{~b}, 20}$ In addition, the 
characteristic benzylic resonance at $\delta=5.43 \mathrm{ppm}$ split upon lowering the temperature, supporting the involvement of this group in the fast equilibria (Figures S18-S19).

These results highlight a crucial difference between $\mathbf{1}$ and $\mathbf{2}$. While the carboxylate group in the axial pyridine of $\mathbf{1}$ binds very strongly to the ruthenium, the alcohol in $\mathbf{2}$ is more labile and can coordinate and decoordinate easily at room temperature.
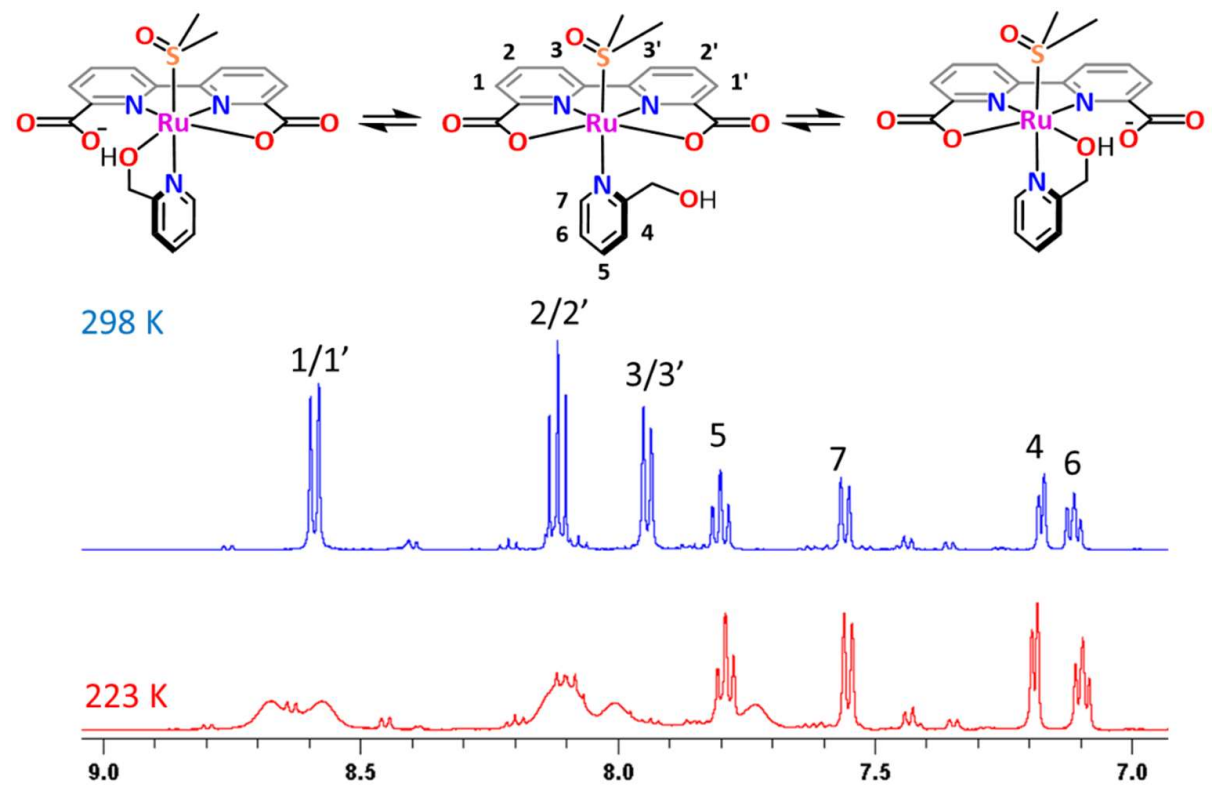

Figure 3. Zoom of the aromatic region of a ${ }^{1} \mathrm{H}-\mathrm{NMR}$ of $\mathbf{2}$ in $\left[\mathrm{d}_{4}\right]-$ Methanol at $223 \mathrm{~K}$ (Red) and $298 \mathrm{~K}$ (blue).

Compound $\mathbf{2}$ is also more reactive than $\mathbf{1}$, as it was possible to substitute the DMSO axial ligand for a pic ligand to give compound [Ru(bda)(pic)(pyA)], $\mathbf{4}$, as indicated in Scheme 1. Compound $\mathbf{4}$ is fairly air sensitive and gets oxidized to its Rulll derivative leading to further decomposition when exposed to open atmosphere for prolonged times. It was fully characterized by spectroscopic and analytical techniques as described in detail in the experimental section. The ${ }^{1} \mathrm{H}$ NMR spectrum of 4 shows a symmetric bda- backbone, indicating that in solution this compound is involved in a fast dynamic behavior analogous to that of its parent compound $\mathbf{2}$ (Figures S20-S25). In an attempt to crystallize compound 4, we obtained the derivative product 5 in Figure 2 which is the result of the oxidation of the benzylic alcohol to a methyl ester group. Indeed, benzylic groups are prone to oxidation, which could be a consequence of the nucleophilic attack of a methanol solvent molecule used in the crystallization mixture, to the electrophilic carbon of the coordinated alcohol group. Alternatively, the close proximity of the methylene group in 4 to a putative high valent and strongly oxidizing $\mathrm{Ru}-\mathrm{OH}$ or $\mathrm{Ru}=\mathrm{O}$ group could also be responsible of the oxidation to a carboxylic acid that esterifies in the presence of 
methanol. ${ }^{21}$ The formation of the $\mathrm{Ru}-\mathrm{OH}$ or $\mathrm{Ru}=\mathrm{O}$ reactive species implies i) oxidation of the initial Ru" by air and ii) the coordination of an aquo ligand coming from moisture in the crystallization solvent. 


\section{2-Electrochemistry of 1 and 2}

The electrochemical properties of complexes $\mathbf{1}$ and $\mathbf{2}$ were investigated in aqueous solution at $\mathrm{pH} 1$ and $\mathrm{pH} 7$ by means of cyclic voltammetry (CV) and differential pulse voltammetry (DPV). In this manuscript all potentials are reported versus the normal hydrogen electrode (NHE).

The cyclic voltammetry of compound $1 \mathrm{in} \mathrm{pH} 1$ ( Figure 4) shows a quasi-reversible wave at $E_{1 / 2}=1.12 \mathrm{~V}$ with a rather low peak to peak separation $(\Delta E=48 \mathrm{mV})$ suggesting that either an adsorption phenomenon or a twoelectron process is taking place at this potential. Analysis of the $i_{p}$ of the anodic peak versus the square root of the scan rate $(u)$ gives a good linear fit, pointing to a homogeneous phase electron transfer process (Figure S27). In addition, a plot of the $\log i_{\mathrm{p}}$ versus logu shows a linear trend with a slope of 0.54 , supporting a high homogeneous contribution to the process. ${ }^{22}$ From these experiments, we tentatively assign the wave at $E_{1 / 2}=$ $1.12 \mathrm{~V}$ to a two-electron process, where $E^{2}<E^{1}$ in Scheme 2, which could be a consequence of the formation of a putative seven coordinated species at oxidation state $\mathrm{Ru}^{\mathrm{IV}}$. In the second $\mathrm{CV}$ scan, a new wave appears at $E_{1 / 2}^{3}=0.54 \mathrm{~V}(\Delta E=59 \mathrm{mV})$, that we attribute to a $\mathrm{Ru}-\mathrm{OH}_{2} / \mathrm{Ru}-\mathrm{OH}$ complex, that is formed upon substitution of one of the carboxylate groups by a water solvent molecule at high oxidation states (Scheme 2 , bottom). This assignment is supported by the $\mathrm{pH}$ dependence behavior of this wave and because it does not appear when compound $\mathbf{1}$ is analyzed in organic solvents (Figure S28). This type of carboxylato/aquo substitution is common in Ru-bda type of complexes. ${ }^{20}$ Three additional weak redox processes at $E \approx 0.26 \mathrm{~V}, E \approx 0.98 \mathrm{~V}$ and $E \approx 1.40 \mathrm{~V}$ also appear after the first scan (see also Figure S26). We attribute them to side-products derived from DMSO ligand oxidation or to isomers of complex 1 that differ in the coordination modes of the bda ${ }^{2-}, \mathrm{pyC}$ or DMSO ligands. The intensities of these waves are higher at $\mathrm{pH} 7$ (Figure S26). At this $\mathrm{pH}$, the redox wave at $E_{1 / 2}^{1}=$ $1.12 \mathrm{~V}$ is not fully reversible, consistent with the presence of higher amount of side-products. In addition, a redox wave appears at $E_{1 / 2}=0.30 \mathrm{~V}(\Delta E=80 \mathrm{mV})$ at $\mathrm{pH} 7$ after sweeping the cycle to the second wave, which corresponds to the Ru-OH$/ \mathrm{Ru}-\mathrm{OH}$ complex that appears at $E_{1 / 2}^{3}=0.54 \mathrm{~V}$ at $\mathrm{pH} 1$.

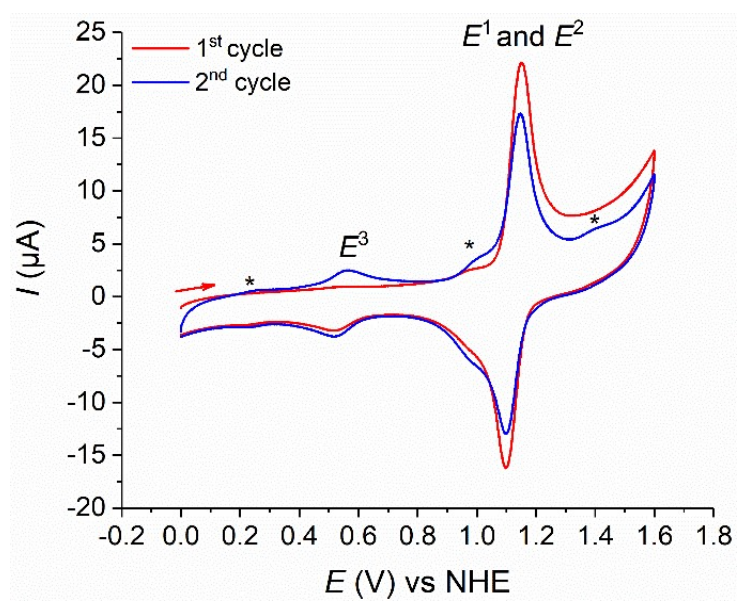

Figure 4. Two consecutive $\mathrm{CV}$ cycles of 1 at $\mathrm{pH} 1(\mathrm{TfOH}=0.1 \mathrm{M}), \mathrm{v}=100 \mathrm{mV} / \mathrm{s}$. [Ru]: $1 \mathrm{mM}$, WE: glassy carbon electrode; CE: platinum electrode; $\mathrm{RE}: \mathrm{Hg} / \mathrm{Hg}_{2} \mathrm{SO}_{4}$. Asterisks ( ${ }^{*}$ ) show unidentified redox waves. 

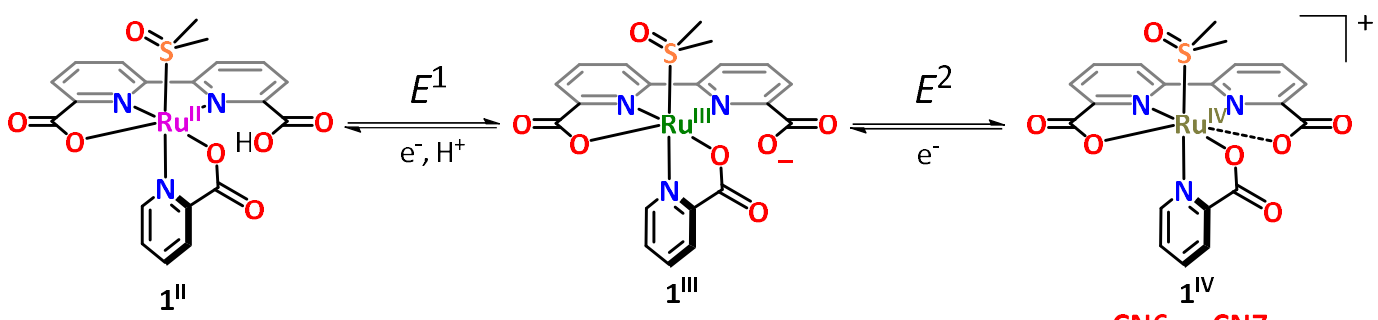

CN6 or CN7
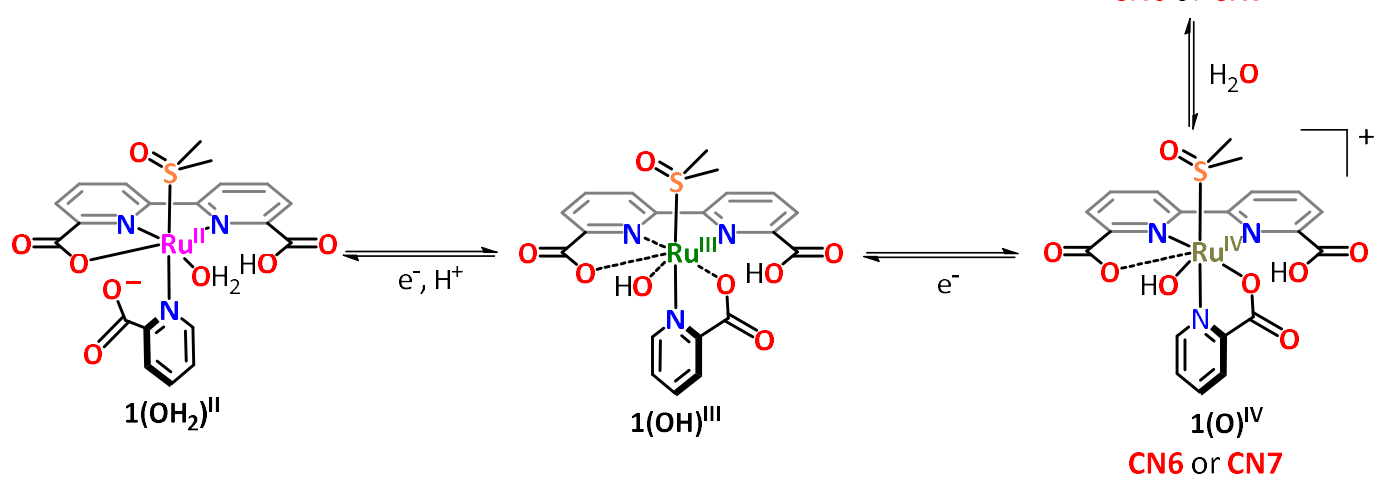

Scheme 2. Reactions involved in the redox chemistry of $\mathbf{1 .}$

Despite the similarities in the coordination environment of complexes $\mathbf{1}$ and $\mathbf{2}$ in the solid state structures depicted in Figure 2, the cyclic voltammetry of $\mathbf{2}$ shows a very different redox profile when compared to that of 1 . In the first scan of a cyclic voltammetry at $\mathrm{pH} 1$ compound 2 shows two redox processes at $E_{1 / 2}^{4}=0.83 \mathrm{~V}$ $(\Delta E \approx 127 \mathrm{mV})$ and $E_{1 / 2}^{5}=1.06 \mathrm{~V}(\Delta E \approx 262 \mathrm{mV})$ associated with the $\mathrm{Ru}^{\mathrm{III} / \mathrm{II}}$ and $\mathrm{Ru} \mathrm{U}^{\mathrm{IV} / \mathrm{III}}$ couples respectively (red trace in Figure 5). The first wave is $\mathrm{pH}$ dependent and appears at $E_{1 / 2}^{4}=0.51 \mathrm{~V}(\Delta E=95 \mathrm{mV})$ at $\mathrm{pH} 7$ (blue trace in Figure 5). The Nernstian behavior of the first wave $E^{4}$ is a clear indication that a proton coupled electron transfer (PCET) process is taking place. ${ }^{23}$ As shown in Scheme 3, this PCET is attributed to the Ru ${ }^{\text {III/II }}$ couple with concomitant proton loss from the coordinated alcohol. The Ru ${ }^{\mathrm{IV} / I I}$ oxidation wave of $\mathbf{2}$ is $\mathrm{pH}$ independent and appears at $E_{1 / 2}^{5}=1.06 \mathrm{~V}(\Delta E=141 \mathrm{mV})$ at $\mathrm{pH} 7$. In the cathodic scan of the cyclic voltammetry of 2 in $\mathrm{pH} 7$ solution, a new redox wave appears at $E_{\mathrm{c}} \approx 0.55 \mathrm{~V}$ only when the anodic scan is swept beyond the second oxidation while the first wave at $E_{1 / 2}^{4}=0.51 \mathrm{~V}$ decreases in intensity (see also Figure S29 and S30). This phenomenon also occurs at pH 1 and is progressive upon cycling (Figure S31). These results suggest that 2 converts to a new species that we attribute to DMSO ligand oxidation, to the oxidation of the pyA ligand to give the corresponding carboxylic acid pyC ligand or both. Indeed, the new wave appearing upon scanning appears at $E \approx 1.1 \mathrm{~V}$, in a very similar potential to that observed for compound 1 containing the carboxylate group. 


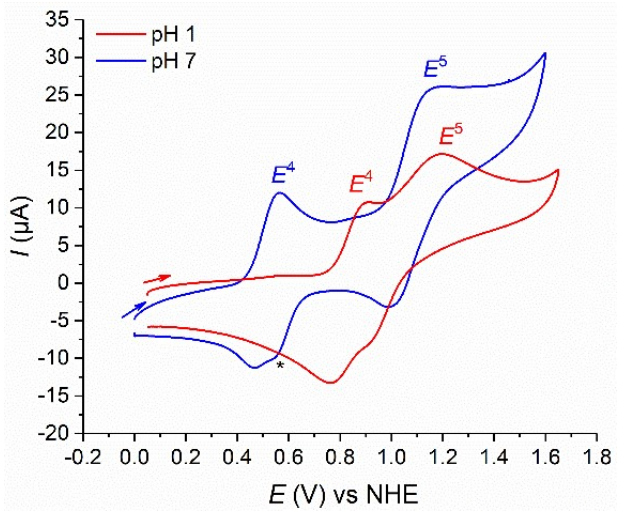

Figure 5. $\mathrm{CV}$ of 2 at $\mathrm{pH} 1$ (blue) and $\mathrm{pH} 7$ (red). Conditions: $\mathrm{pH} 1(\mathrm{TfOH}=0.1 \mathrm{M}), \mathrm{pH} 7$ (phosphate buffer aqueous solution), v = $100 \mathrm{mV} / \mathrm{s}$. [Cat]: $1 \mathrm{mM}$, WE: glassy carbon electrode; CE: platinum electrode; $\mathrm{RE}: \mathrm{Hg} / \mathrm{Hg}_{2} \mathrm{SO}_{4}$. Black arrow shows the scan direction. Asterisk $(*)$ shows unidentified redox wave that appears only after scanning the second oxidation wave.
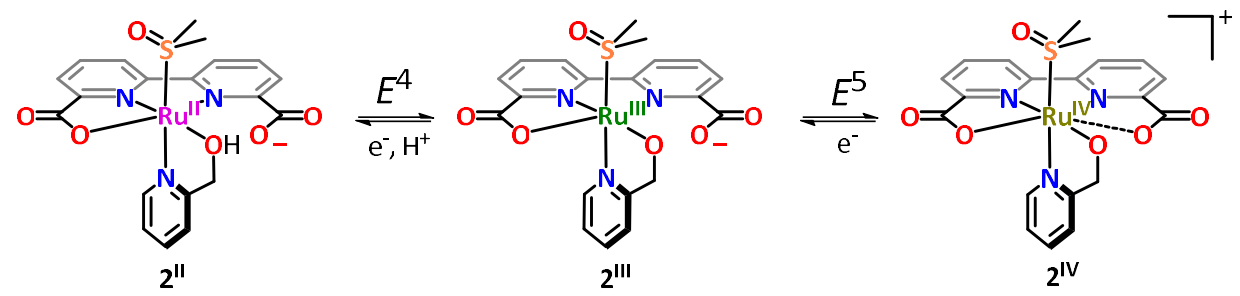

Scheme 3. Reactions involved in the redox chemistry of $\mathbf{2}$. 


\section{3-Electrochemistry of 4 and its transformation to a water oxidation catalyst}

The electrochemical properties of complex 4 were investigated in aqueous solution at $\mathrm{pH} 7$ by means of $\mathrm{CV}$, DPV and bulk electrolysis experiments.

The first CV scan of a solution of 4 in $\mathrm{pH} 7$ shows a complex behavior with five waves appearing at $E_{1 / 2}^{6}=0.64$ $\mathrm{V}(\Delta E \approx 66 \mathrm{mV}), E_{1 / 2}^{7}=0.86 \mathrm{~V}(\Delta E \approx 89 \mathrm{mV}), E_{1 / 2}^{8}=1.0 \mathrm{~V}(\Delta E \approx 74 \mathrm{mV}), E_{\mathrm{p}, \mathrm{a}}^{9}=1.33 \mathrm{~V}$ and $E_{\mathrm{p}, \mathrm{a}}^{10}=1.42 \mathrm{~V}$ (Figure 6 , left). Upon cycling in the potential range from $0.1 \mathrm{~V}$ to $1.6 \mathrm{~V}$, the $\mathrm{CV}$ profile simplifies leaving only the reversible waves $E^{6}$ and $E^{8}$ (Figure 6 , right and Figure S31). In addition, the appearance of a very intense, irreversible wave at $E_{\text {onset }} \approx 1.4 \mathrm{~V}$ appears upon cycling, that we tentatively attribute to water oxidation catalysis. Indeed, a bulk electrolysis experiment of a solution of $\mathbf{4}$, shows a steady current versus time profile upon applying a potential of $E_{\mathrm{app}}=1.5 \mathrm{~V}$, indicative of a catalytic process (Figure 7 and Figure S35). Importantly, the waves at $E^{6}$ and $E^{8}$ are fully recovered after the catalytic wave, a proof of the integrity of the complex upon turnover. These two waves are $\mathrm{pH}$ independent and are consistent with two successive one-electron oxidations from $\mathrm{Ru}^{\prime \prime}$ to $\mathrm{Ru}^{\mathrm{IV}}$ of a complex that do not contain a Ru-OH 2 group (Figure S33). Thus, the aquo ligand must coordinate at the $\mathrm{Ru}^{\mathrm{IV}}$ or $\mathrm{Ru}^{\mathrm{V}}$ oxidation states to form a Ru-oxo/hydroxo species responsible of triggering the catalysis. A foot of the wave analysis (FOWA) of a cyclic voltammetry containing the catalytic species gives a maximum turnover frequency (TOF $\mathrm{Tax}_{\text {) }}$ of $0.63-0.74 \mathrm{~s}^{-1}$ (Figure S34).
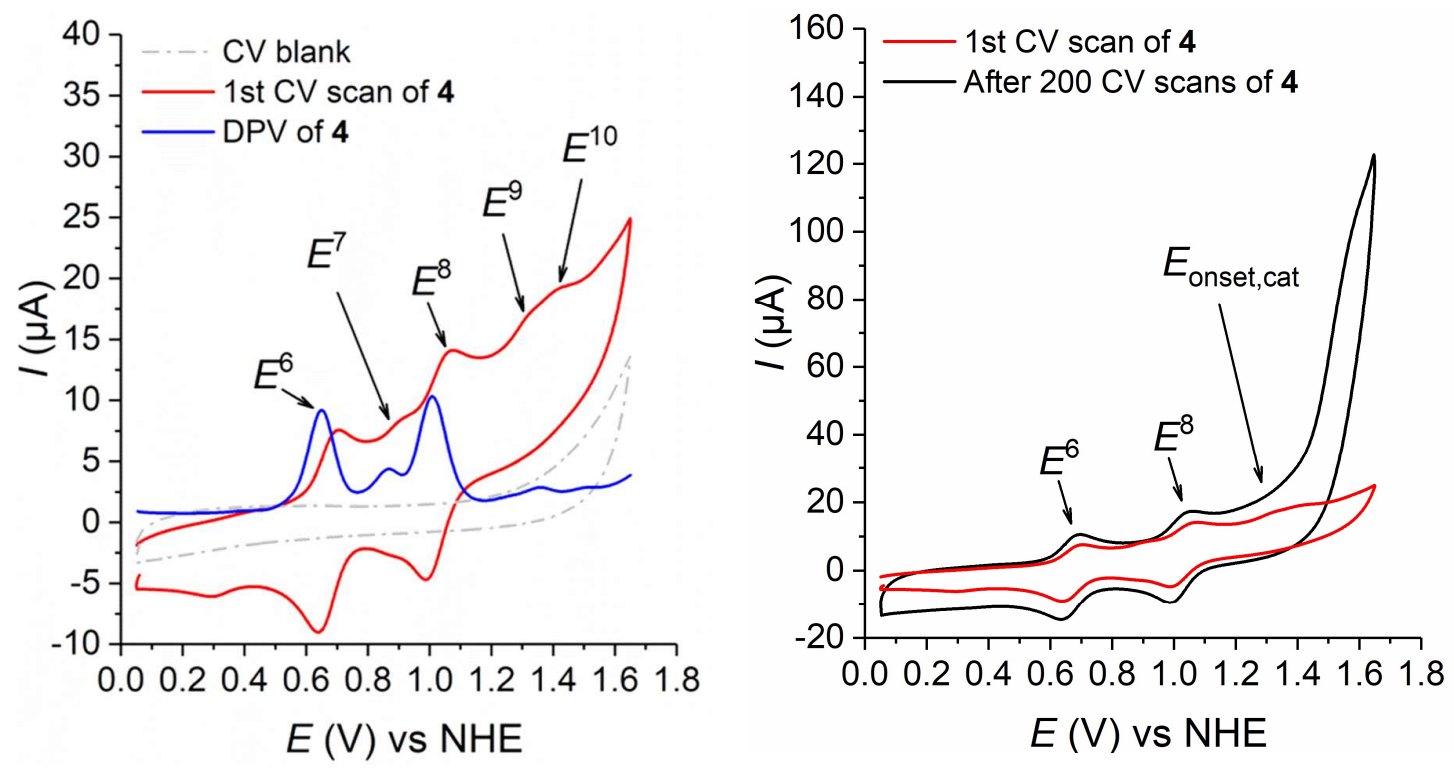

Figure 6.Left) First CV scan of $\mathbf{4}$ in a phosphate buffer aqueous solution at pH 7. Right) Comparison of CV of $\mathbf{4}$ before (red) and after 200 cycles (black). [Ru]: $1 \mathrm{mM}, \mathrm{v}=100 \mathrm{mV} / \mathrm{s}, \mathrm{WE}$ : glassy carbon electrode; CE: platinum electrode; RE: $\mathrm{Hg} / \mathrm{Hg}_{2} \mathrm{SO}_{4}$. 


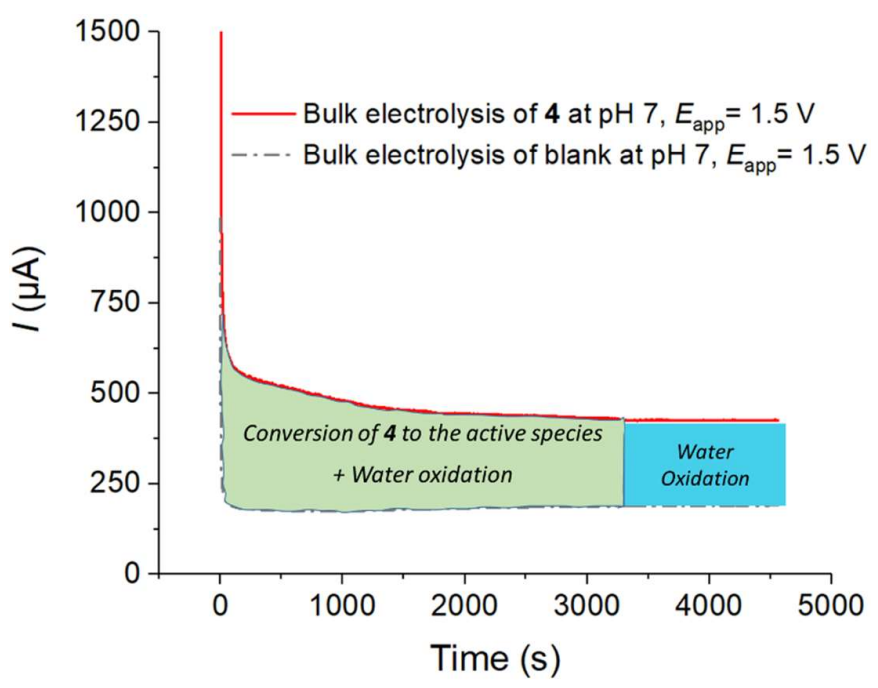

Figure 7. Bulk electrolysis of 4 in a phosphate buffer solution at $\mathrm{pH} 7$ solution at $E_{\mathrm{app}}=1.5 \mathrm{~V}$. During the first 55 minutes, complex $\mathbf{4}$ converts to an active complex (green area). From this time, the current passed is attributed to the water oxidation catalysis process by the active species, giving a TON $=587$, based on the active catalyst on the surface, see supporting information. ${ }^{24}$ Conditions: $[\mathrm{Ru}]=1 \mathrm{mM}$, Volume $=3 \mathrm{~mL}, E_{\mathrm{app}}=1.5 \mathrm{~V}, \mathrm{WE}$ : glassy carbon rod, CE: Pt mesh electrode (simple square mesh net $20 * 20 \mathrm{~mm}$ ), $\mathrm{RE}: \mathrm{Hg} / \mathrm{Hg}_{2} \mathrm{SO}_{4}$.

\section{4-Discussion}

The first attempt towards the synthesis of the target compound [Ru(bda)(pic)(pyC)], 3, from the intermediate $[\mathrm{Ru}(\mathrm{Hbda})(\mathrm{DMSO})(\mathrm{pyC})], \mathbf{1}$, by substitution of the DMSO ligand by pic was unsuccessful due to the low reactivity of $\mathbf{1}$. Thus, an alternative route based on the intermediate $[R u(b d a)(p i c)(p y A)], 4$, successfully prepared from [Ru(bda)(DMSO)(pyA)], 2, was pursued. The distinct reactivity towards DMSO substitution of related compounds $\mathbf{1}$ and $\mathbf{2}$ can be understood from their respective unique structural and electronic features. While the carboxylate group of the axial pyC ligand is strongly bound to the ruthenium, the alcohol group in the pyA ligand is labile and is involved in a dynamic behaviour in solution. This is demonstrated by low temperature ${ }^{1} \mathrm{H}$ NMR experiments that show a non-symmetric nature of the bda- ligand while analogous experiments done at room temperature show a perfectly symmetric compound, a result of an averaged of all the species involved in the equilibrium (Figure 3). In addition, the electrochemical behaviour of $\mathbf{1}$ and $\mathbf{2}$ are radically different. Compound $\mathbf{2}$ shows two consecutive one-electron oxidation, as expected for this type of complexes. In sharp contrast, complex 1 shows a complex redox behavior with a main wave that has been assigned to a single two-electron oxidation event, likely a consequence of the favored seven coordination (CN7) environment around the metal center upon oxidation (Scheme 2). ${ }^{1 a, 25}$

The benzylic alcohol in $\mathbf{4}$ is susceptible to oxidation, and upon exposure to the air in a methanolic solution it produces the ester derivative 5 in Figure 2. This is the first indication of the feasibility of preparing the desired complex $\mathbf{3}$ by oxidation of the alcohol precursor $\mathbf{4}$ in the absence of an esterification agent. Indeed, the methylene group in the ortho-position of the pyridine ligand pyA is situated in a very close proximity to the 
ruthenium center, which can catalyze the reaction. This oxidation can be accelerated electrochemically, by cycling towards oxidative potentials to produce a high valent ruthenium complex, which can coordinate a

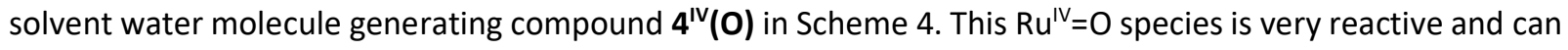
undergo the oxidation of the alcohol to carboxylic acid through an oxygen transfer reaction that would produce the target compound 3 . $^{21}$ This hypothesis is supported by the electrochemical behaviour of $\mathbf{4}$ in water, summarized in Figure 6. While the first scan of a cyclic voltammetry experiment shows a complex profile with five redox waves, indicative of a mixture of species present in solution, it progressively evolves towards a much simpler profile. As shown in the black trace of Figure 6 (right), only two consecutive one-electron oxidation waves are observed, attributed to the $\mathrm{Ru}^{\mathrm{III} / I}$ and $\mathrm{R \textrm {u } ^ { \mathrm { IV } } / \mathrm { III }}$ redox couples, followed by a catalytic process with $E_{\text {onset }}$ $=1.4 \mathrm{~V}$. This behavior is fully consistent with complex $\mathbf{3}$, which at low oxidation state, does not coordinate any aqua ligand due to the strong binding of the carboxylate of the axial pyC ligand leading to two $\mathrm{pH}$ independent redox events (Scheme 4, bottom, and Table 1). However, at high oxidation states, the possibility to reach CN7 facilitates the coordination of a water molecule producing the Ru-oxo species $\mathbf{3}(\mathbf{0})^{\mathrm{IV}}$, which is further oxidized to $\mathbf{3}(\mathbf{O})^{\mathrm{v}}$ before catalysis starts. At $\mathrm{pH} \mathrm{7}$, the dangling carboxylate group in $\mathbf{3}(\mathbf{0})^{\mathrm{v}}$ is deprotonated and can better assist the water nucleophilic attack of a water molecule to the $\mathrm{Ru}=\mathrm{O}$ group in the $\mathrm{O}-\mathrm{O}$ bond formation step by accepting a proton of the incoming water.

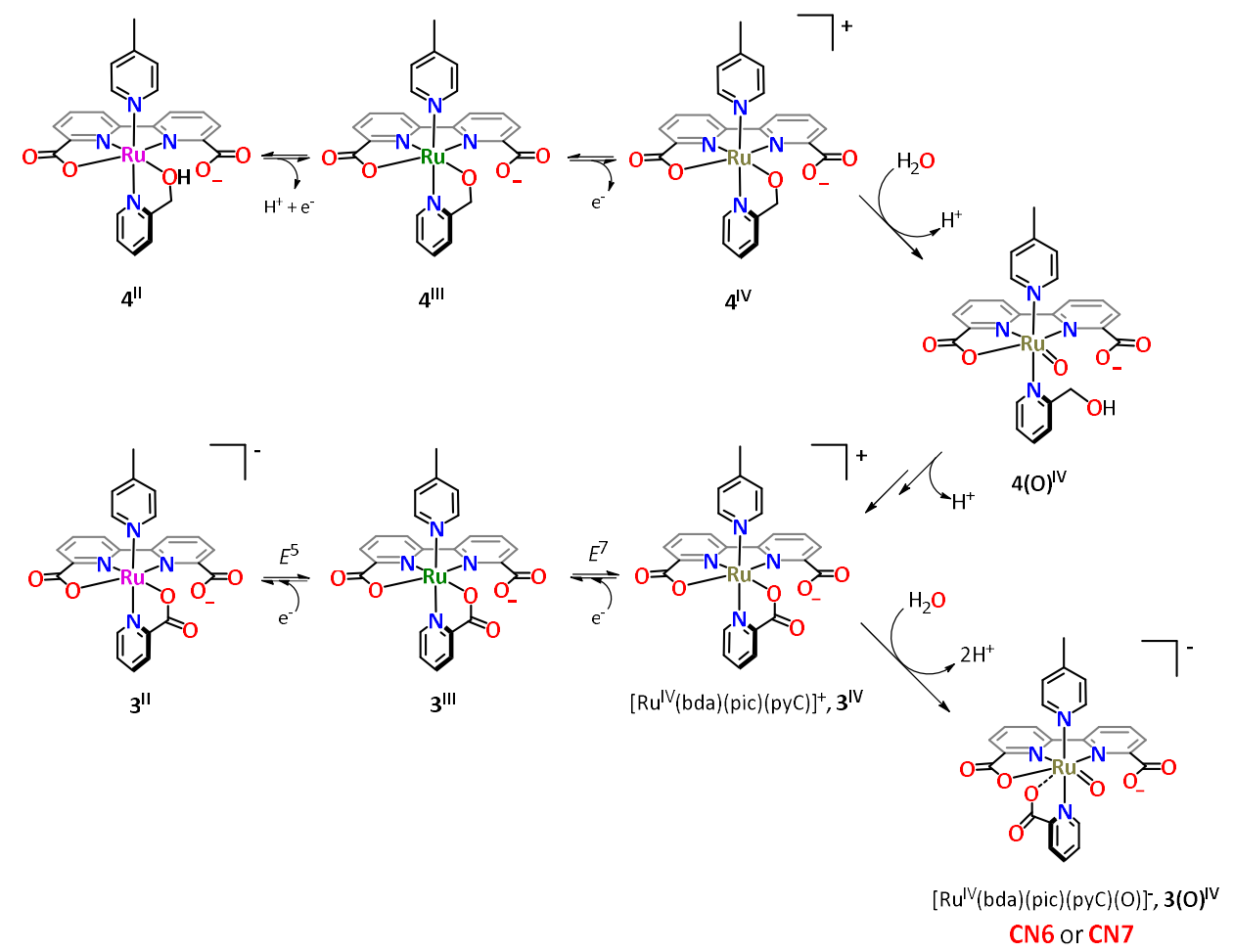

Scheme 4. Putative mechanism to form the active water oxidation catalyst, 3(0), after bulk electrolysis of 4 in a phosphate buffer solution at $\mathrm{pH} 7$ and at $E_{\mathrm{app}}=1.5 \mathrm{~V}$. 
Foot of the wave analysis of the cyclic voltammetry of a solution containing electrogenerated $\mathbf{3}$ accounts for a TOF $_{\max }=0.63-0.74 \mathrm{~s}^{-1}$ assuming a water nucleophilic attack mechanism. This value is one of the highest reported in the literature but it is significantly lower than that of the widely used and related $\left[\mathrm{Ru}(\mathrm{bda})(\mathrm{pic})_{2}\right]$ complex with TOF $\max =11 \mathrm{~s}^{-1}$ based on a mechanism involving the interaction of two $\mathrm{M}=0$ groups (Table 1 ). ${ }^{3 \mathrm{a}}$ ${ }^{25}$ Complexes 3 and $\left[\mathrm{Ru}(\mathrm{bda})(\mathrm{pic})_{2}\right]$ have a similar coordination sphere with four pyridine type of ligands and two carboxylate groups. However, they have a significantly different geometry; while compound $\left[\mathrm{Ru}(\mathrm{bda})(\mathrm{pic})_{2}\right]$ shows a highly distorted octahedral geometry due to the wide O-Ru-O angle around $124^{\circ}$ provided by the bda ${ }^{2-}$ ligand, complex $\mathbf{3}$ is expected to be close to the ideal octahedral coordination with a $\mathrm{O}$ Ru-O around $90^{\circ}$, as suggested by the XRD structures of $(1-\mathrm{H})^{-}$and $\mathbf{5}$ in Figure 2 . This is a consequence of the chelate effect of the axial pyC ligand, that strongly binds to the ruthenium leaving a carboxylate of the bda ${ }^{2-}$ ligand dangling. This key feature can determine the final geometry of the reactive $3(0)^{v}$, which can be either six or seven coordinated, influencing the overpotential of the reaction. ${ }^{26}$

Another key feature of $\mathbf{3}$ that differs from compound $\left[\mathrm{Ru}(\mathrm{bda})(\mathrm{pic})_{2}\right]$ is the presence of a dangling carboxylate group if the active $\mathbf{3}(\mathbf{O})^{\mathrm{v}}$ is CN7 or even two dangling carboxylate groups if it has CN6 (Scheme 4). Interestingly, this is not enough to outperform the high catalytic activity of the fastest molecular water oxidation catalyst reported to date $\left[\mathrm{Ru}(\mathrm{tda})(\mathrm{py})_{2}\right]$ with $\operatorname{TOF}_{\max }=7700 \mathrm{~s}^{-1}$ (Table 1$) \cdot{ }^{3 \mathrm{~b}}$ The latter is characterized by a unique mechanism based on a water nucleophilic attack assisted by the well positioned dangling carboxylate group of the equatorial ligand (Table 1).

Table 1. Electrochemical and water oxidation data at $\mathrm{pH} 7$ for complex 3 and structurally related compounds $\left[\mathrm{Ru}(\mathrm{bda})(\mathrm{pic})_{2}\right]$ and $\left[\mathrm{Ru}(\mathrm{tda})(\mathrm{py})_{2}\right]$ reported in the literature.

\begin{tabular}{|c|c|c|c|c|c|}
\hline \multirow{2}{*}{ Ru complex } & \multicolumn{3}{|c|}{$E$ in volts vs NHE at $\mathrm{pH} 7$} & \multirow{2}{*}{$\begin{array}{c}\text { TOF }_{\max }{ }^{[a]} \\
\left(s^{-1}\right)\end{array}$} & \multirow{2}{*}{ Ref. } \\
\hline & $\mathrm{Ru}^{\mathrm{III} / \|}$ & $\mathrm{Ru}^{\mathrm{IV} / \mathrm{III}}$ & $E_{\text {cat,onset }}$ & & \\
\hline$\left[R u^{\prime \prime \prime}\left(\kappa-N^{2} O^{1}-b d a\right)(p i c)\left(\kappa-N^{1} O^{1}-p y C\right)\right], 3$ & $0.65^{[b]}$ & $1.01^{[b]}$ & $1.4^{[\mathrm{c}]}$ & $0.63-0.74$ & This work \\
\hline$\left[R u^{\prime \prime}\left(\kappa-N^{2} O^{2}-b d a\right)(p i c)_{2}\right]$ & 0.55 & 0.82 & 1.1 & 11 & 3a, 27 \\
\hline$\left[R u^{\prime \prime}\left(\kappa-N^{3} \mathrm{O}^{1}-\mathrm{tda}\right)(\mathrm{py})_{2}\right]$ & $0.55^{[b]}$ & $1.10^{[\mathrm{b}]}$ & $1.3^{[\mathrm{c}]}$ & 7700 & $3 b, 27$ \\
\hline
\end{tabular}

[a] Calculated using the FOWA method ${ }^{27}$ and assuming a mechanism based on the interaction between two $M=0$ groups $(\mathrm{I} 2 \mathrm{M})$ for $\left[\mathrm{Ru}^{\prime \prime}\left(\mathrm{K}-\mathrm{N}^{2} \mathrm{O}^{2}-\mathrm{bda}\right)(\mathrm{pic})_{2}\right.$ ] and a water nucleophilic attack mechanism (WNA) for 3 and $\left[\mathrm{Ru}^{\prime \prime}\left(\mathrm{K}-\mathrm{N}^{3} \mathrm{O}^{1}-\mathrm{tda}\right)(\mathrm{py})_{2}\right]$. [b] Data for the complex with no hydroxo/oxo coordinated to the ruthenium. [c] Data for the ruthenium oxo species that forms only at high oxidation states. 


\section{5-Conclusions}

An intramolecular oxidation of the benzylic alcohol of complex $[\mathrm{Ru}(\mathrm{bda})(\mathrm{pic})(\mathrm{pyA})], \mathbf{4}$, allowed us to prepare the corresponding carboxylic acid complex $[\mathrm{Ru}(\mathrm{bda})(\mathrm{pic})(\mathrm{pyc})], \mathbf{3}$, in situ by electrochemical techniques. Compound $\mathbf{3}$ is a precursor of a water oxidation catalyst that has similar coordination sphere to those of wellknown $\left[\mathrm{Ru}(\mathrm{bda})(\mathrm{pic})_{2}\right]$ and $\left[\mathrm{Ru}(\mathrm{tda})(\mathrm{py})_{2}\right]$ complexes, which are very active catalysts.

While the catalytic results obtained for 3 are amongst the best reported to date, with TOF $_{\max }=0.63-0.74 \mathrm{~s}^{-1}$ at an onset potential of $1.4 \mathrm{~V}$, it doesn't overcome the results obtained for [Ru(bda)(pic $\left.)_{2}\right]$ and $\left[\mathrm{Ru}(\mathrm{tda})(\mathrm{py})_{2}\right]$ under the same experimental conditions $\left(\mathrm{TOF}_{\max }=11 \mathrm{~s}^{-1}\right.$ at $1.1 \mathrm{~V}$ and $\mathrm{TOF}_{\max }=7700 \mathrm{~s}^{-1}$ at $1.3 \mathrm{~V}$, respectively). We attribute the lower performance of $\mathbf{3}$ to the different geometrical requirements of the equatorial and axial ligands. In particular, to the stabilization effect of the pyridine-2-carboxylate ligand ( $p y C)$ in $\mathbf{3}$ that binds in a bidentate fashion and leaves a dangling carboxylate from the $\mathrm{bda}^{2-}$ axial ligand. As a consequence, $\mathbf{3}$ adopts a coordination sphere that is close to a perfect octahedral geometry with angles around $90^{\circ}$, as observed for the related compounds $[\mathrm{Ru}(\mathrm{bda})(\mathrm{DMSO})(\mathrm{pyC})],(\mathbf{1 - H})^{-}$, and $\mathbf{5}$ in Figure 2, that were studied in the solid state. In sharp contrast, the axial ligands in $\left[\mathrm{Ru}(\mathrm{bda})(\mathrm{pic})_{2}\right]$ and $\left[\mathrm{Ru}(\mathrm{tda})(\mathrm{py})_{2}\right]$ are monodentate, thus the equatorial ligands $\mathrm{bda}^{2-}$ and $\mathrm{tda}^{2-}$ act as tetradentate ligands, forcing a distorted octahedral geometry with O-Ru-O and $\mathrm{Neq}_{\text {eq }}$ - Ru-O angles of $124^{\circ}$ and $141^{\circ}$ at oxidation state $\mathrm{Ru}^{\prime \prime}$, respectively. In addition, the tda $\mathrm{a}^{2-}$ ligand can act as a pentadentate ligand at Rulv forming a CN7 complex. These characteristics together with additional second coordination sphere effects, provide the optimum electronic and geometric features to undergo fast water oxidation catalysis.

This work highlights the importance of geometry around the ruthenium metal center in complexes that are active for the water oxidation catalysis. It also provides evidence of the reactivity of Ru towards intramolecular oxidation of neighboring benzylic groups.

\section{Acknowledgements}

Support from MINECO, FEDER and AGAUR are gratefully acknowledged through grants CTQ2016-80058-R, CTQ2015-73028-EXP, SEV 2013-0319, ENE2016-82025-REDT, CTQ2016-81923-REDC, and 2017-SGR-1631. A. G. thanks MINECO for a FPI grant (BES-2015-073069).

\section{Supporting Information}

Additional crystallographic, spectroscopic, mass spectrometry and electrochemistry data. 


\section{References}

1. (a) Matheu, R.; Ertem, M. Z.; Gimbert-Suriñach, C.; Sala, X.; Llobet, A., Seven Coordinated Molecular Ruthenium-Water Oxidation Catalysts: A Coordination Chemistry Journey. Chemical Reviews 2019, 119 (6), 3453-3471; (b) Matheu, R.; Garrido-Barros, P.; Gil-Sepulcre, M.; Ertem, M. Z.; Sala, X.; Gimbert-Suriñach, C.; Llobet, A., The development of molecular water oxidation catalysts. Nature Reviews Chemistry 2019, 3 (5), 331-341; (c) Tong, L.; Thummel, R. P., Mononuclear ruthenium polypyridine complexes that catalyze water oxidation. Chemical Science 2016, 7 (11), 6591-6603.

2. (a) Creus, J.; Matheu, R.; Peñafiel, I.; Moonshiram, D.; Blondeau, P.; Benet-Buchholz, J.; García-Antón, J.; Sala, X.; Godard, C.; Llobet, A., A Million Turnover Molecular Anode for Catalytic Water Oxidation. Angewandte Chemie International Edition 2016, 55 (49), 15382-15386; (b) Richmond, C. J.; Matheu, R.; Poater, A.; Falivene, L.; Benet-Buchholz, J.; Sala, X.; Cavallo, L.; Llobet, A., Supramolecular Water Oxidation with Rubda-Based Catalysts. Chemistry - A European Journal 2014, 20 (52), 17282-17286.

3. (a) Duan, L.; Bozoglian, F.; Mandal, S.; Stewart, B.; Privalov, T.; Llobet, A.; Sun, L., A molecular ruthenium catalyst with water-oxidation activity comparable to that of photosystem II. Nature chemistry 2012, 4 (5), 418-423; (b) Matheu, R.; Ertem, M. Z.; Benet-Buchholz, J.; Coronado, E.; Batista, V. S.; Sala, X.; Llobet, A., Intramolecular proton transfer boosts water oxidation catalyzed by a Ru complex. Journal of the American Chemical Society 2015, 137 (33), 10786-10795.

4. (a) Matheu, R.; Moreno-Hernandez, I. A.; Sala, X.; Gray, H. B.; Brunschwig, B. S.; Llobet, A.; Lewis, N. S., Photoelectrochemical Behavior of a Molecular Ru-Based Water-Oxidation Catalyst Bound to TiO2Protected Si Photoanodes. Journal of the American Chemical Society 2017, 139 (33), 11345-11348; (b) Grau, S.; Berardi, S.; Moya, A.; Matheu, R.; Cristino, V.; Vilatela, J. J.; Bignozzi, C. A.; Caramori, S.; Gimbert-Suriñach, C.; Llobet, A., A hybrid molecular photoanode for efficient light-induced water oxidation. Sustainable Energy \& Fuels 2018, 2 (9), 1979-1985.

5. Matheu, R.; Francàs, L.; Chernev, P.; Ertem, M. Z.; Batista, V.; Haumann, M.; Sala, X.; Llobet, A., Behavior of the Ru-bda water oxidation catalyst covalently anchored on glassy carbon electrodes. ACS Catalysis 2015, 5 (6), 3422-3429.

6. Evans, I. P.; Spencer, A.; Wilkinson, G., Dichlorotetrakis(dimethyl sulphoxide)ruthenium(II) and its use as a source material for some new ruthenium(II) complexes. Journal of the Chemical Society, Dalton Transactions 1973, (2), 204-209.

7. (a) Wang, L.; Mirmohades, M.; Brown, A.; Duan, L.; Li, F.; Daniel, Q.; Lomoth, R.; Sun, L.; Hammarström, L., Sensitizer-catalyst assemblies for water oxidation. Inorganic chemistry 2015, 54 (6), 2742-2751; (b) The exact composition of this intermediate in the solid state is not fully elucidated through elemental analysis. It is only soluble in DMSO solvent giving pure $[\mathrm{Ru}(\mathrm{bda})(\mathrm{DMSO}) 2]$ that is the result of the substitution of $X$ by DMSO.

8. Data collection and reduction with CrysAlisPro 1.171.39.12b (Rigaku OD, 2015).

9. Berardi, S.; Drouet, S.; Francas, L.; Gimbert-Suriñach, C.; Guttentag, M.; Richmond, C.; Stoll, T.; Llobet, A., Molecular artificial photosynthesis. Chemical Society Reviews 2014, 43 (22), 7501-7519.

10. Data collection with APEX II version v2013.4-1. Bruker (2007). Bruker AXS Inc., Madison, Wisconsin, USA.

11. Data reduction with Bruker SAINT version V8.30c. Bruker (2007). Bruker AXS Inc., Madison, Wisconsin, USA.

12. SADABS: V2012/1 Bruker (2001). Bruker AXS Inc., Madison, Wisconsin, USA. Blessing,. Acta Crystallographica 1995, A51, 33-38.

13. SHELXT; V2014/4 (Sheldrick 2014). Sheldrick, G. M., Acta Crystallographica 2015, A71, 3-8.

14. SHELXle; C.B. Huebschle, G. M. S., B. Dittrich, SHELXle;. Journal of Applied Crystallography 2011, 44, $1281-1284$

15. SHELXL; SHELXL-2014/7 (Sheldrick 2014). Sheldrick, G. M., Acta Crystallographica 2015, C71, 3-8.

16. (a) Spek, A. L., SQUEEZE implemented in Platon. Platon:. Journal of Applied Crystallography 2003, 36, 7-13; (b) A.L., S., SQUEEZE: . Acta Crystallographica 2015, C71, 9-18. 
17. Wang, L.; Mirmohades, M.; Brown, A.; Duan, L.; Li, F.; Daniel, Q.; Lomoth, R.; Sun, L.; Hammarström, L., Sensitizer-Catalyst Assemblies for Water Oxidation. Inorganic chemistry 2015, 54 (6), 2742-2751.

18. (a) Duan, L.; Fischer, A.; Xu, Y.; Sun, L., Isolated Seven-Coordinate Ru(IV) Dimer Complex with $[\mathrm{HOHOH}]-$ Bridging Ligand as an Intermediate for Catalytic Water Oxidation. Journal of the American Chemical Society 2009, 131 (30), 10397-10399; (b) Wang, L.; Duan, L.; Stewart, B.; Pu, M.; Liu, J.; Privalov, T.; Sun, L., Toward Controlling Water Oxidation Catalysis: Tunable Activity of Ruthenium Complexes with Axial Imidazole/DMSO Ligands. Journal of the American Chemical Society 2012, 134 (45), 18868-18880.

19. (a) Tong, L.; Duan, L.; Xu, Y.; Privalov, T.; Sun, L., Structural modifications of mononuclear ruthenium complexes: a combined experimental and theoretical study on the kinetics of ruthenium-catalyzed water oxidation. Angewandte Chemie International Edition 2011, 50 (2), 445-449; (b) Duan, L.; Wang, L.; Inge, A. K.; Fischer, A.; Zou, X.; Sun, L., Insights into Ru-based molecular water oxidation catalysts: Electronic and noncovalent-interaction effects on their catalytic activities. Inorganic chemistry 2013, 52 (14), 7844-7852.

20. Matheu, R.; Ghaderian, A.; Francàs, L.; Chernev, P.; Ertem, M. Z.; Benet-Buchholz, J.; Batista, V. S.; Haumann, M.; Gimbert-Suriñach, C.; Sala, X.; Llobet, A., Behavior of Ru-bda Water-Oxidation Catalysts in Low Oxidation States. Chemistry - A European Journal 2018, 24 (49), 12838-12847.

21. Garrido-Barros, P. F., I.; Farràs, P.; Gimbert-Suriñach, C.; Maseras, F.; Llobet, A, Water as an oxygen source for oxidation reactions from "Catalytic oxidation in organic synthesis". . Edited by Muñiz, K. Thieme Chemistry - Stuttgart 2017, 63-77.

22. Bard, A. J.; Faulkner, L. R.; Leddy, J.; Zoski, C. G., Electrochemical methods: fundamentals and applications. wiley New York: 1980; Vol. 2.

23. Weinberg, D. R.; Gagliardi, C. J.; Hull, J. F.; Murphy, C. F.; Kent, C. A.; Westlake, B. C.; Paul, A.; Ess, D. H.; McCafferty, D. G.; Meyer, T. J., Proton-coupled electron transfer. Chemical Reviews 2012, 112 (7), 40164093.

24. (a) Costentin, C.; Drouet, S.; Robert, M.; Savéant, J.-M., Turnover numbers, turnover frequencies, and overpotential in molecular catalysis of electrochemical reactions. Cyclic voltammetry and preparative-scale electrolysis. Journal of the American Chemical Society 2012, 134 (27), 11235-11242; (b) Zhang, T.; Wang, C.; Liu, S.; Wang, J.-L.; Lin, W., A biomimetic copper water oxidation catalyst with low overpotential. Journal of the American Chemical Society 2013, 136 (1), 273-281.

25. Hoque, M. A.; Benet-Buchholz, J.; Llobet, A.; Gimbert-Suriñach, C., Catalytic Oxidation of Water to Dioxygen by Mononuclear Ru Complexes Bearing a 2,6-Pyridinedicarboxylato Ligand. ChemSusChem 2019, 12 (9), 1949-1957.

26. Matheu, R.; Ertem, M. Z.; Gimbert-Suriñach, C.; Benet-Buchholz, J.; Sala, X.; Llobet, A., Hydrogen Bonding Rescues Overpotential in Seven-Coordinated Ru Water Oxidation Catalysts. ACS Catalysis 2017, 7 (10), 6525-6532.

27. Matheu, R.; Neudeck, S.; Meyer, F.; Sala, X.; Llobet, A., Foot of the Wave Analysis for Mechanistic Elucidation and Benchmarking Applications in Molecular Water Oxidation Catalysis. ChemSusChem 2016, 9 (23), 3361-3369. 


\section{Graphical Abstract}

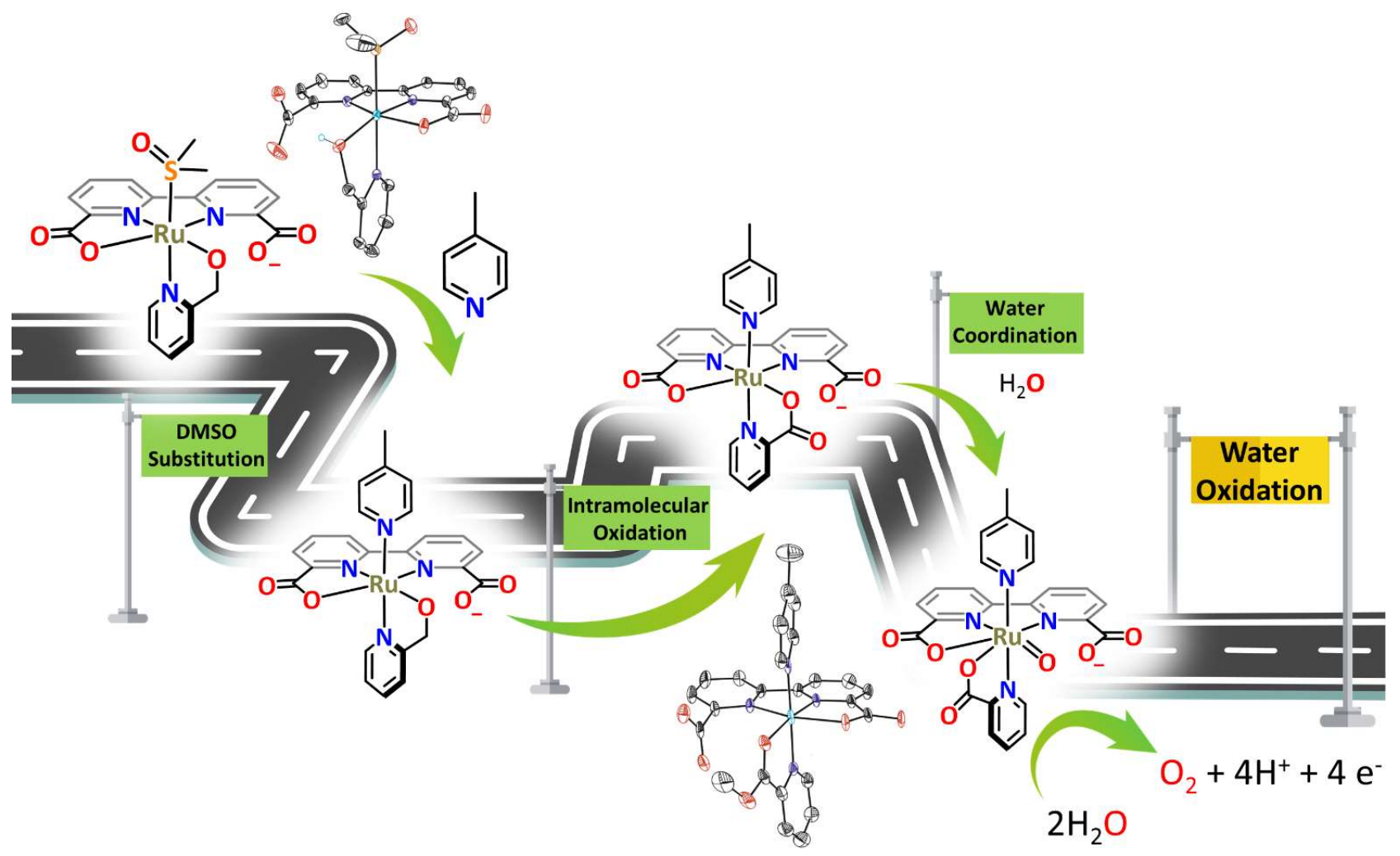

\section{Synopsis}

Intramolecular oxidation of a benzylic alcohol by a high valent ruthenium-oxo group of a non-symmetric Rubda complex leads to an active catalyst for the water oxidation catalysis, which is characterized by leaving a dangling carboxylate of the bda equatorial ligand that coordinates in a tridentate mode. The geometrical and electronic characteristics of this catalyst provide distinct catalytic performance compared to the well-known symmetric Ru-bda complexes, in which the bda ligand binds in a tetradentate fashion. 